\title{
MANAGEMENT OF SUSTAINABLE, CREDIBLE AND INTEGRATED ELECTRONIC VOTING (E-VOTING) SYSTEM FOR BANGLADESH
}

\author{
M. Mesbahuddin, SARKER ${ }^{1}$, M Nazrul, ISLAM ${ }^{2}$ \\ ${ }^{1}$ Jahangirnagar University, Bangladesh, mail.sarker@yahoo.com \\ ${ }^{2}$ Jahangirnagar University, Bangladesh, islam_ju@yahoo.com
}

\begin{abstract}
In this modern age countries worldwide evince a growing interest in electronic voting (e-Voting), which brings the idea of modernizing elections through electronic systems and provides many advantages such as efficiency, disseminating results more quickly, and in a cost-effective way. The paper gives a brief overview on recent developments of electronic voting systems in Bangladesh by using electronic voting machine (EVM) and addresses some strategies and principles in order to improve accessibility, easiness, accuracy, and security of election for better democratic process.
\end{abstract}

KEY WORDS: E-Voting, Electronic Voting Machine (EVM), E-Government, E-Democracy.

\section{INTRODUCTION}

Electronic voting has gained widespread use in many countries all over the world and has already proven to speed up the counting of votes as well as improve turnout among disabled voters. This technology can include punched cards, optical scan voting systems and specialized voting kiosks (including selfcontained direct-recording electronic voting systems, or DRE). It can also involve transmission of ballots and votes via telephones, private computer networks, or the Internet. Therefore, electronic voting is a term encompassing several different types of voting, embracing both electronic means of casting a vote and electronic means of counting votes. Several countries however have expressed concern over the possibility that electronic voting can lead to massive electoral fraud.

In 2002 Brazil was the first member of the United Nations to conduct a large-scale national election using e-Voting technology. According to the United Nations that was the biggest election on the planet using e-Voting technologies. The same year more than 100 million people, many of them living below the poverty line used electronic machines to vote, by typing a candidate number into this machine. The media all over the world was astonished by the fact that the "days of transporting paper election ballots through the Amazon by canoe" were over [Hamilton 2002]. However, the media pointed out that investment in this election was expensive, by figuring out that hundreds of million dollars had been spent on software and hardware. 100 million voters cast their ballots on more than 406,000 touch-screen machines scattered all over the country. But nobody still knows the exact cost of large-scale elections in Brazil using e-Voting technology. At present, Internet voting systems have also gained popularity and have been used for government elections and referendums in the United Kingdom, Estonia and Switzerland as well as municipal elections in Canada and party primary elections in the United States and France ${ }^{1}$. Nowadays electronic voting is also used in other countries like: Norway, Germany, Belgium, Romania, Australia, Italy, Ireland, European Union and France.

\footnotetext{
REMOTE VOTING TECHNOLOGY, Chris Backert e-Government Consulting
}

With electronic voting machines (EVMs), the Kerala province in India, conducted its election in 1982. Since then a long time has passed away experimenting on EVM. Meanwhile, other countries in Europe and America also experimented on EVM from technical and transparency point of view. Also electronic voting systems for electorates have been in use since the $1960 \mathrm{~s}^{2}$ when punched card systems debuted. Their first widespread use was in the USA where 7 counties switched to this method for the 1964 presidential election ${ }^{3}$.

In Bangladesh, EVM was first used partially in Chittagong City Corporation (ChCC) election in 2010 and then in Narayanganj City Corporation (NCC) election in 2011. At the beginning of 2012 this technology was used fully in Comilla City Corporation (CCC) election and in Narshingdy Municipal election, but again partially in Rangpur City Corporation election (RCC) at the end of 2012. Based on the abovementioned experience, Election Commission of Bangladesh (ECB) and the present government would like to use electronic voting machine (EVM) increasingly for any local election in hopes of introducing it in the national election (likely to be held in 2014).

Electronic voting machines (EVMs) contain a memory chip and a removable memory card. When voters cast their ballot, votes are recorded to the chip and the removable memory card. At the end of an election, poll workers remove the memory card and take it to a tabulation center, where the cards are loaded onto a computer and the votes are tabulated to produce unofficial election results. Over the next couple of days when official tallies are made, election officials compare votes stored on the memory chip with those tabulated from the memory cards to ensure that no one changed votes on the cards after they were removed from the machines. Some e-voting machines have modems that allow poll workers to send unofficial results through a phone line to the tabulation center.

\section{DEFINITION OF TERMS}

- E-voting - refers to an election that involves the use of electronic means at least in the process of casting the vote

\footnotetext{
${ }^{2}$ Bellis, Mary. The History of Voting Machines

${ }^{3}$ Saltman, Roy. EFFECTIVE USE OF COMPUTING TECHNOLOGY IN VOTE-TALLYING. NIST.
} 
[Ajiboye et. al. 2013]. Voting is a process with an important role in a democratic society.

- Electronic Voting Machine - an instrument for recording and counting votes. It is a combination of mechanical, electromechanical, or electronic equipment that is used to define ballots; to cast and count votes; to report or display election results. The voting machine itself is generally positioned in a booth, often closed off by a curtain to assure secrecy for the voter.

- E-Government - refers to the use by government agencies of information technologies (such as Wide Area Networks, the Internet, and mobile computing) that have the ability to transform relations with citizens, businesses, and other arms of government.

- E-Democracy - consists of all electronic means of communication that enable/empower citizen in their efforts to hold rulers/politicians accountable for their actions in the public realm [Trechsel 2005].

\section{RELATED WORKS ON E-VOTING}

The introduction of e-Voting raises some of the same challenges faced when applying electronics to any other subject, for example e-Government [Susanne 2010]. It is a fundamental right of any individual to vote, as this is to prevent unwanted politicians from gaining access to the position of governance and to choose new representatives. In the digital era, technology influences the way people uphold democracy included in elections. The paper-ballot which prevails in conventional elections could be replaced with electronic items such as computers. The new system is called electronic voting or e-Voting. The goal of e-voting is generally to improve accessibility, easiness, accuracy, and security of election for better democratic process [Alvarez 2005]. Therefore the issue e-Voting has increasingly become a topic among political commentators and political scientists. Researchers [Trechsel 2005], [Alvarez et at. 2004], [Loncke et at. 2004] and [Coleman 2002] have focused on the political and legal issues related to e-Voting, the aspects of designing e-Voting systems have been less covered. However, Electronic voting has many advantages over the traditional way of voting. Some of these advantages are lower cost, faster tabulation of results, improved accessibility, greater accuracy, and lower risk of human and mechanical errors. Some arguments in favor of eVoting focus on the potentially increased participation both in terms of quantity and quality are more covered [Braun 2005] and [Trechsel 2005].

Formerly when elections were made traditionally, organizers determined the eligibility of voters and who should not even move close to polling stations. This may involve a formal registration period or making a formal announcement of age of voters or other factors that may make one eligible to vote. Once the election begins, the administrator may validate the credentials of those attempting to vote [Feras et. al. 2011]. Contrary to the traditional way of voting, electronic voting is essential because it considers ways in which the polling tasks can be performed electronically without sacrificing voter privacy or introducing opportunities for fraud. In order to determine whether a system performs these tasks well, it is useful however, to develop a set of criteria for evaluating system performance. The criteria to be developed are such as accuracy, democracy, convenience, flexibility, privacy, verifiability and mobility [Nurmi et. al. 1991].

For an election to be considered free and fair it is expected to meet some international standards. The open rights group in 2007 opined some of those listed include accuracy, security and verifiability. Also, voters are only allowed one anonymous ballot each, which they can mark in privacy [ORG 2007]. For an election to withstand the test of time, it must be robust and be ready to withstand a variety of fraudulent behaviors. It must also be sufficiently transparent and comprehensible so that voters and losers can accept the results of the election [Tadayoshi 2004]. The Council of Europe mentioned that some motives for e-Voting implementation relate to the easy and accessibility of election participation. Other motives are about benefits of cost reduction and an efficient administration process [Remmert 2004]. Despite those benefits, some stakeholders feel discouraged to apply e-voting. E-voting is deemed vulnerable from fault, fraud, and other types of cyber crime [Obaed 2011]. The discouragement of e-Voting also occurs because it brings high potential risks in politics. A failed voting causes serious politics problems. For those reasons, eVoting has to be implemented successfully only if followed by good strategy and practices [Aprilia at el.].

The strategies of e-Voting implementation need to consider critical success factors (CSFs) as essential components defined by Pinto [Pinto 1987]. Because CSFs are certain strategic factors which have to be well-achieved to get the success of goal and targets. Pinto addressed CSFs as "some factors which, addressed, significantly improve project implementation changes" The CSFs approach helps election management to maintain and focus on those significant factors in order to keep project on the right path.

\section{EXISTING E-VOTING SYSTEMS}

According to the place, time, location and technology, electronic voting systems can be identified into two quite different types [Buchsbaum 2004], [Zissis et al. 2011] and [Adrian 2011] as below:

- I-voting or remote e-Voting: Those that use the Internet and

- E-voting: Those that do not use the Internet

\subsection{I-Voting}

As the use of the Internet spread rapidly in the 1990s and early 21 st century, it seemed that the voting process would naturally migrate there. In this scenario, voters would cast their choices from any computer connected to the Internet-including from their home. This type of voting mechanism is sometimes referred to as I-voting. That means, remote e-Voting where voting is performed within the voter's sole influence, and is not physically supervised by representatives of governmental authorities (e.g. voting from one's personal computer, mobile phone, cybercafe, television via the internet (I-voting).

\subsection{E-Voting}

Because of security and access concerns, most large-scale electronic voting is currently held in designated precincts using special-purpose machines. This type of voting mechanism is referred to as e-Voting. That means, e-Voting is physically supervised by representatives of governmental or independent electoral authorities (e.g. electronic voting machines located at polling stations). According to the nature of device and machinery, four types of e-Voting systems are identified as:

- $\quad$ Paper based e-Vote system;

- Direct Recording Electronic (DRE) system;

- Punch card voting/Tabulation system;

- Optical scanning system

\subsubsection{Paper-based e-Voting System}

In a paper based e-Voting system, a touch screen is used in voting. After the voter has finished casting his votes, the unit prints out a hardcopy of the ballot which the voter has to pass 
to the election officer in charge so that it can be counted in a centralized location. The ballots will then be counted through optical-scan voting systems. This system has the advantage of a paper trail as every person \& apposes votes are recorded on a piece of paper.

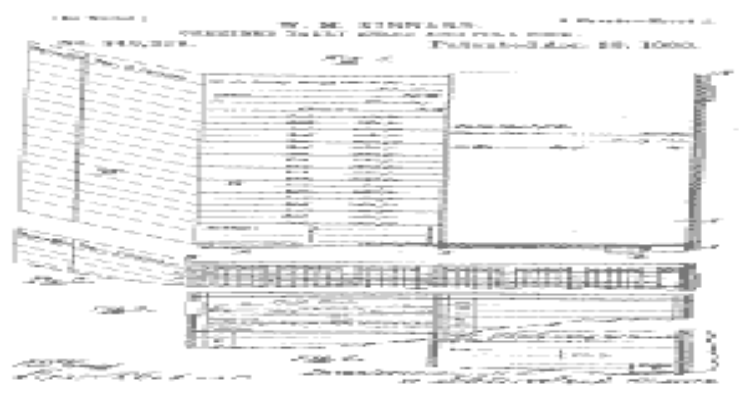

Paper Ballot

\subsubsection{Direct Recording Electronic (DRE) System}

This is essentially voting facilitated by a computer. Here, a digital swipe-card, buttons or a touch screen are used in order to make the choices. The votes are stored in a physical memory device which be sent to a centralized voting station. Public network DRE voting systems can send the results after each voter has finished or by batches throughout the Election Day through the Internet.

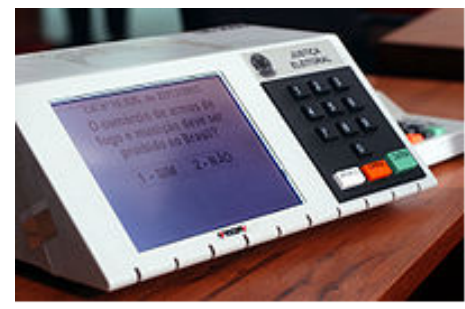

DRE Voting Machine

\subsubsection{Punch Card Voting/Tabulation System}

With punch card systems, voters punch holes in cards using a supplied punch device, to indicate votes for their chosen candidates. After voting, the voter may feed the card directly into a computer vote tabulating device at the polling place, or the voter may place the card in a ballot box, which is later transported to a central location for tabulation. Punch cards and computer tally machines were first used in the U.S. for the 1964 Presidential primary election in two counties in the State of Georgia.

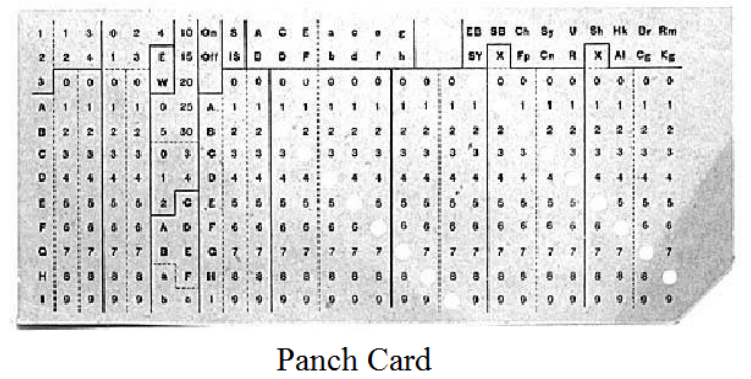

\subsubsection{Optical Scanning System}

An electronic voting system uses an optical scanner to read marked paper ballots and tally the results. An advantage of this system is that the voters do not have to learn how to use a voting machine. Physically able voters can simply use pen and paper to mark their intent. Some disabled voters could use a machine to print a voted ballot, which can then be fed into the optical scanner along with all the other ballots, thus preserving the secrecy of their ballot.

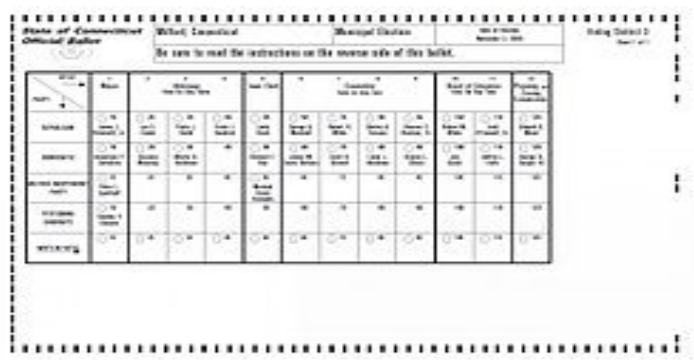

Optical Marked Paper

\section{E-VOTING FRAMEWORK AND PROTOCOLS}

Electronic voting schemes have to follow a set of protocols in order to ensure a robust, accurate, secure and quality-based design and implementation. There are a number of protocols for e-Voting systems such as Actors of e-Voting, Principles of e-Voting, and Requirements of e-Voting.

\subsection{Main Actors of e-Voting}

Voting is regarded as one of the most effective methods for individuals to express their opinions on a given topic. E-voting refers to the use of computers or computerized voting equipment to cast ballots in an election. Chaum pioneered the notion of e-Voting and then many protocols were proposed [Chaum 2000]. The first practical e-Voting protocol for large scale elections is proposed by Fujioka [Fujioka et al. 1992].

The basic process of any e-Election is fairly standardized although a wide variety of e-Voting systems and protocols exist. According to them any e-Voting system should include the following actors (Table 1).

Table 1. Main Actors of e-Voting

\begin{tabular}{|c|l|}
\hline Actors & \multicolumn{1}{|c|}{ Purpose } \\
\hline Voter & $\begin{array}{l}\text { Voter has the right for voting, and he } \\
\text { votes in the election. }\end{array}$ \\
\hline Registration & $\begin{array}{l}\text { Registration authority or authorities } \\
\text { register eligible voters before the } \\
\text { election day. These authorities ensure } \\
\text { that only registered voters can vote } \\
\text { and they vote only once on the election } \\
\text { day. Registration authorities may be } \\
\text { registrar, authenticator, authorizer, } \\
\text { ballot distributor and/or key generator. }\end{array}$ \\
\hline Tallying & $\begin{array}{l}\text { The tallying authorities collect the cast } \\
\text { votes and tally the results of the } \\
\text { election. Tallying authorities may be } \\
\text { counter, collector and/or taller. }\end{array}$ \\
\hline
\end{tabular}

Therefore, any e-Voting system should also involve these four phases as below (Table 2):

Table 2. Four Phases of e-Voting

\begin{tabular}{|c|l|}
\hline Phases & \multicolumn{1}{|c|}{ Purpose } \\
\hline Registration & $\begin{array}{l}\text { Voters register themselves to registration } \\
\text { authorities and the list of eligible voters is } \\
\text { compiled before the election day. }\end{array}$ \\
\hline $\begin{array}{c}\text { Authentication } \\
\text { and }\end{array}$ & $\begin{array}{l}\text { On the election day registered voters } \\
\text { request ballot or voting privilege from the } \\
\text { registration authorities Registration } \\
\text { authorities check the credentials of those } \\
\text { attempting to vote and only allow those } \\
\text { who are eligible and registered before. }\end{array}$ \\
\hline Voting & Voter casts his/her vote. \\
\hline Tallying & $\begin{array}{l}\text { The tallying authorities count the votes } \\
\text { and announce the election results. }\end{array}$ \\
\hline
\end{tabular}


A general e-Voting process and the actors involved can be summarized as in Figure [Cetinkaya et al. 2007], [Cranor et al. 1997] and [Fujioka et al. 1992].

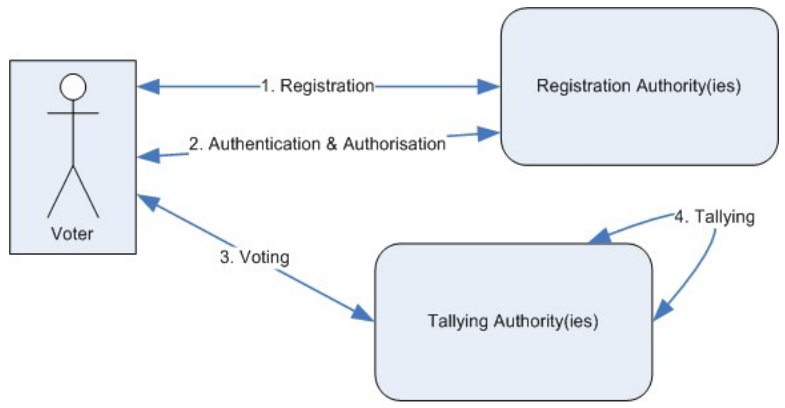

A General e-Voting Process

\subsection{Basic Principles of e-Voting}

The main principle of e-Voting is that it must be as similar to traditional voting as possible, compliant with election legislation and principles and be at least as secure as traditional voting. From a technical point of view the e-Voting system must be simple as well as transparent [Ülle lepp et al. 2007]. Some basic principles of e-Voting are as follows (Table 3).

Table 3. Basic Principles of e-Voting

\begin{tabular}{|c|l|}
\hline Principles & \multicolumn{1}{|c|}{ Purpose } \\
\hline $\begin{array}{c}\text { For voter } \\
\text { identification } \\
\text { ID-cards are } \\
\text { used }\end{array}$ & $\begin{array}{l}\text { The ID-card is the only independent } \\
\text { means of electronic communication, } \\
\text { which enables electronic personal } \\
\text { authentication at a maximum security } \\
\text { level and digital signature. }\end{array}$ \\
\hline $\begin{array}{c}\text { Possibility of } \\
\text { electronic re- } \\
\text { vote }\end{array}$ & $\begin{array}{l}\text { e-Voter can cast his/her vote again and } \\
\text { the previous vote will be deleted. }\end{array}$ \\
\hline $\begin{array}{c}\text { The priority of } \\
\text { traditional } \\
\text { voting }\end{array}$ & $\begin{array}{l}\text { Should the voter go to polling station } \\
\text { prior to the voting day and cast a vote, } \\
\text { his or her electronically cast vote shall } \\
\text { be deleted. }\end{array}$ \\
\hline
\end{tabular}

\subsection{Basic Requirements of e-Voting}

Electronic voting has a very complex set of security requirements [Gritzalis 2002]. As such, it is one of the most valuable exploratory areas for the pursuance of a secure eGovernment transaction environment. In specialized literature, there are various e-Voting requirements mentioned in e-Voting protocols. Some of those are as follows (Table 4).

Table 4. Basic Requirements of e-Voting

\begin{tabular}{|c|l|}
\hline Requirements & \multicolumn{1}{|c|}{ Purpose } \\
\hline Privacy & $\begin{array}{l}\text { It is the inability to link a voter to a } \\
\text { vote. Voter privacy must be preserved } \\
\text { during the election as well as after the } \\
\text { election for a long time. }\end{array}$ \\
\hline Eligibility & $\begin{array}{l}\text { Only eligible voters participate in the } \\
\text { election. They should register before } \\
\text { the election day and only registered } \\
\text { eligible voters can cast votes. }\end{array}$ \\
\hline Uniqueness & $\begin{array}{l}\text { Only one vote for a voter should be } \\
\text { counted. It is important to notice that } \\
\text { uniqueness does not mean un- } \\
\text { reusability, where voters should not } \\
\text { vote more than once. }\end{array}$ \\
\hline
\end{tabular}

\begin{tabular}{|c|c|}
\hline Uncoercibility & $\begin{array}{l}\text { Any coercer, even authorities, should } \\
\text { not be able to extract the value of the } \\
\text { vote and should not be able to coerce a } \\
\text { voter to cast his vote in a particular } \\
\text { way. Voter must be able to vote freely. }\end{array}$ \\
\hline Receipt-freeness & $\begin{array}{l}\text { It is the inability to know what the vote } \\
\text { is. Voters must neither be able to obtain } \\
\text { nor construct a receipt which can prove } \\
\text { the content of their vote to a third party } \\
\text { both during the election and after the } \\
\text { election ends. This is to prevent vote } \\
\text { buying or selling. }\end{array}$ \\
\hline Fairness & $\begin{array}{l}\text { No partial tally is revealed before the } \\
\text { end of the voting period to ensure that } \\
\text { all candidates are given a fair decision. } \\
\text { Even the counter authority should not } \\
\text { be able to have any idea about the } \\
\text { results. }\end{array}$ \\
\hline Transparency & $\begin{array}{l}\text { The whole voting process must be } \\
\text { transparent. Bulletin boards may be } \\
\text { used to publicize the election process. } \\
\text { The security and reliability of the } \\
\text { system must not rely on the secrecy of } \\
\text { the network, which cannot be } \\
\text { guaranteed. }\end{array}$ \\
\hline Accuracy & $\begin{array}{l}\text { All cast votes should be counted. Any } \\
\text { vote cannot be altered, deleted, } \\
\text { invalidated or copied. Any attack on the } \\
\text { votes should be detected. Uniqueness } \\
\text { should also be satisfied for accuracy. }\end{array}$ \\
\hline Robustness & $\begin{array}{l}\text { Any number of parties or authorities } \\
\text { cannot disrupt or influence the election } \\
\text { and final tally. To have confidence in } \\
\text { the election results, robustness should } \\
\text { be assured. However, there are } \\
\text { numerous ways for corruption. For } \\
\text { example; registration authorities may } \\
\text { cheat by allowing ineligible voters to } \\
\text { register; ineligible voters may register } \\
\text { under the name of someone else; ballot } \\
\text { boxes, ballots and vote counting } \\
\text { machines may be compromised. }\end{array}$ \\
\hline
\end{tabular}

\section{E-VOTING IN THE CONTEXT OF BANGLADESH}

What are the factors or standards a nation has to consider in order to determine if it's ready for adopting or modernizing its e-Voting system? Robert Krimmer [Krimmer Robert et al. 2008], from the Competence Center for e-Voting and Participation in Vienna, have proposed an e-Voting Readiness Index.

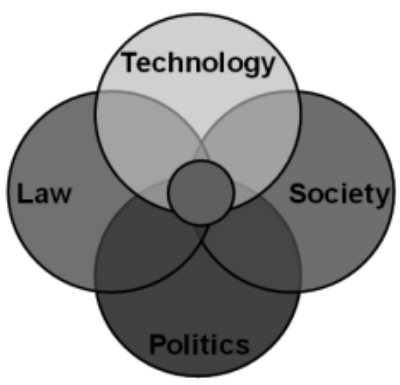

Four Dimensions of e-Voting 
They analyzed several countries under different criteria such as their information society context, legal and political circumstances and e-Voting application. Krimmer and Schuster expected to find a higher level of inclination in countries where computer and Internet penetration was high and e-Government standards had been developed. Based on these decisive factors, results were ranked in an effort to see which criteria would affect each country's readiness to adopt e-Voting. However finally they concluded that there are no formulas to determine which nations are ready to implement a transformation in their systems. A clear willingness to change is the first of several important factors that should be considered. Leens and Svenson [Leens et al. 2003] considered four major dimensions in order to develop a model of e-Voting system. These are: the political, legal, technological and social dimensions. But for the context of Bangladesh (according to present digital opportunities, political and other socioeconomic prospects) the following seven dimensions need to be considered for e-Voting readiness (Table 5).

Table 5. Preparation for e-Voting in Bangladesh

\begin{tabular}{|c|c|c|}
\hline No. & Dimensions & Purpose \\
\hline 1. & $\begin{array}{l}\text { ICT Infrastructure } \\
\text { Readiness }\end{array}$ & $\begin{array}{l}\text { Covering issues of ICT } \\
\text { infrastructure in the government } \\
\text { and across the nation. }\end{array}$ \\
\hline 2. & $\begin{array}{l}\text { Technological } \\
\text { Readiness }\end{array}$ & $\begin{array}{l}\text { Covering issues of local ICT } \\
\text { industry to deliver and provide } \\
\text { maintenance services for large } \\
\text { scale e-Governance projects. }\end{array}$ \\
\hline 3. & $\begin{array}{l}\text { Managerial } \\
\text { Readiness }\end{array}$ & $\begin{array}{l}\text { Covering issues of internal } \\
\text { administration and ownership of } \\
\text { the transition process in the } \\
\text { government. }\end{array}$ \\
\hline 4. & Legal Readiness & $\begin{array}{lll}\text { Covering legal issues for } \\
\text { supporting e-Governance. }\end{array}$ \\
\hline 5. & $\begin{array}{l}\text { Human Resource } \\
\text { Readiness }\end{array}$ & $\begin{array}{l}\text { Covering issues of internal } \\
\text { capacity building within the } \\
\text { government offices to take } \\
\text { charge of and maintain IT-based } \\
\text { systems }\end{array}$ \\
\hline 6. & Financial Readiness & $\begin{array}{l}\text { Covering issues of financing the } \\
\text { transition towards e-Governance } \\
\text { and building a sustained } \\
\text { financial model for supporting } \\
\text { and maintain IT-based systems. }\end{array}$ \\
\hline 7. & Political Readiness & $\begin{array}{l}\text { Covering issues of top-level } \\
\text { political commitment and } \\
\text { willingness to deal with } \\
\text { challenges of transition and } \\
\text { learning from initial mistakes. }\end{array}$ \\
\hline
\end{tabular}

\section{PROBLEMS AND SOLUTIONS WITH E- VOTING}

\subsection{Problems}

Electronic voting machines (EVMs) were supposed to be the cure for the malady of booth-capturing in elections in Bangladesh and India too, but in the present form of use they have only worsened the problems. Moreover, EVMs also do not meet the legal requirements set out in the Information Technology Act. Also EVMs can appear to perform properly from the outside, but record votes inaccurately. Without a paper backup trail or some other means to verify votes, there is no meaningful way to determine the integrity of the machines or an election. So EVMs present significant risk. Therefore, before committing to using EVMs in Bangladesh, and to be considered free and fair, the international standards, election commission of Bangladesh (ECB) has to be meeting the following facts regarding total process of an election including EMVs:

- Provides transparency so that public and political party confidence in election results is maintained, particularly amongst election losers.

- Sufficiently tamper proof to prevent manipulation of votes, of vote counts and of election results.

- Provides an audit trail (VVPAT) sufficient to provide evidence of the EVM's integrity and accuracy in case of election result challenges.

- $\quad$ Provides acceptable and easy usable by Bangladeshi voters particularly the illiterate and physically disable voters.

- Needs to be sure that voters are fully educated on the EVM so that political forces cannot successfully spread false stories about their use.

- Needs to be $100 \%$ confident that its staff and deputed officials all have the management skills to successfully operate EVMs in all areas they are used.

- Needs to be aware it is lack of EVM transparency, perceptions of EVM integrity, and possibilities of EVM fraud, not just reality, that have affected public attitudes to EVMs in other countries.

- Individuals have to be accurately identified as eligible voters who have not already voted.

- Voters are allowed only one anonymous ballot each, which they can mark in privacy;

- The ballot box is secure, observed and, during the election, only able to have votes added to it by voters: votes cannot be removed.

- When the election ends, the ballot box is opened and counted in the presence of observers from all competing parties. The counting process cannot reveal how individual voters cast their ballots.

- If the results are in doubt, the ballots can be checked and counted again by different people.

- As far as the individual voter is concerned, he must be assured that the candidate he casts his vote for, actually gets that vote.

- Finally, all contestants must trust and accept the use of the EVMs.

\subsection{Solutions}

Electronic voting systems especially by using EVMs represent a great security challenge. Traditionally, security is incorporated in both hardware and software systems and should be integrated in these both life cycles [D.P. Gilliam 2003 et al.]. However, Professor Matt Bishop addresses the following issues regarding security concerns and issues of EVMs [Kevin Daimi et al.] and [JANOPOP 2012]. These are as follows:

- Security must be part of the design and implementation of the system and not added on 'after the fact'.

- It must not depend upon secrecy (except passwords and cryptographic keys).

- Policies and procedures should be designed with, or drive the design of, the system as it is being designed and implemented.

- Any mechanism must consider not only voters but also poll workers, election officials, and system maintainers.

- Assume some systems will fail; plan to protect votes cast on it, and also to enable voting to continue.

- There must be standards and testing; they must be independent of the developers of the systems. 
- EVM needs to consider the users, operators, and maintainers of the systems. Reports should show what tested, why, and how.

- Penetration testing is a must.

- The voting system should include controls to prevent deliberate or accidental attempts to replace code such as unbounded arrays and strings.

- The system should be zero-tolerant with regard to compromising.

- Election process should not be subject to any manipulation including even a single vote manipulation.

- The system should provide accurate time and date settings.

- The system should not allow improper actions by voters and election officials.

- The system should provide means for protecting and securing recounts of ballots cast in elections.

- The system should not allow voter submissions to be observed or recorded in any way that is traceable to the individual voter.

- The system should ensure that election results would be verifiable to independent observers. This implies that published election results correspond to the ballots cast by legitimate voters.

- The system should not allow tampering with audit logs.

\section{CONCLUSION AND FUTURE WORK}

Voting is one of the most critical features in any democratic process. By casting a vote we hold previous politicians to account and express our hopes for the future. But the voting processes should be fair, accurate and acceptable for all stakeholders. The voting machine's greatest asset is protection against voting fraud or human error. However, critics claim that it intimidates some citizens, that some machines are subject to breakdown, and that fraud is not completely eliminated. Besides, many comments have been made by professionals and officials on electronic voting systems advantages and disadvantages with a special emphasis on their security. Therefore, Bangladesh should carefully reconsider how to achieve a secure and transparent voting system that is suitable to its national values and requirements. Existing EVMs do not have updatable software, but it would be possible to add a VVPAT by interposing on the cable between the control unit and the ballot unit. The experience gained from the five pilot projects and the Recommendation of the Council of Europe has to be taken into account when drafting future legislation on eVoting. The implementation of e-Voting has been undergoing ups and downs recently, from which, respectively, conclusions have to be drawn in order to introduce e-Voting correctly and effectively. Finally it can be said that the work on e-Voting is an ongoing process and the implementation of e-Voting has been undergoing ups and downs recently, from which, respectively, conclusions have to be drawn in order to introduce e-Voting correctly and effectively.

\section{REFERENCES}

1. Adrian Dulaj (2011): SEMINAR WORK: E-ELECTIONS AND E-VOTING - THE CASE OF SWITZERLAND AND FRANCE, University of Fribourg, Switzerland.

2. Ajiboye A. R., Adewole K. S., Jimoh R. G., and Oladipo I. D. (2013): Modeling and Evaluation of E-Voting System for a Sustainable Credible Election: International Journal of Applied Information Systems (IJAIS) - ISSN : 22490868 Foundation of Computer Science FCS, New York, USA Volume 5- No.3, February 2013 - www.ijais.org
3. Alvarez, M. dan Hall, Thad E. (2005): Lessons and Trends in E-voting: Initiatives in the US and Abroad,[online], American Political Science Association Annual Meeting, www.Yate.ca/tech.edu (accessed on 13/04/2011).

4. Alvarez R. M. and T.E. Hall (2004): Point, Click, \& Vote: The Future of Internet Voting Washington, DC: Brookings Institution.

5. Aprilia Hartami and Putu Wuri Handayani : The Critical Success Factors of E-voting Implementation in Indonesian Local Elections: The Case of Jembrana Regency Election: Faculty of Computer Science, Universitas Indonesia, Jakarta, Indonesia.

6. Braun, N (2005): E-voting - worldwide developments, opportunities, risks and challenges, Reflections on the future of democracy in Europe, Strasbourg, Council of Europe Publishing, pps. 115-119.

7. Buchsbaum, T. (2004): E-voting: International developments and lessons learnt". Proceedings of Electronic Voting in Europe Technology, Law, Politics and Society. Lecture Notes in Informatics. Workshop of the ESF TED Programme together with GI and OCG.

8. Cetinkaya, O. and Cetinkaya, D. (2007): Towards Secure E-Elections in Turkey: Requirements and Principles, International Workshop on Dependability and Security in e-Government (DeSeGov'07) - In Proceedings of ARES'07, Vienna, Austria, pp. 903-907.

9. Chaum, David (2000): Secret-Ballot Receipts and Transparent Integrity. David Chaum, draft. Available at http://www.vreceipt.com/article.pdf

10. Coleman S. (2002): Elections in the 21st Century: From Paper Ballot to e-Voting, London: Electoral Reform Society. Available at: http://www.electoralreform.org.uk/oldsite20070123/publications/books/Report. pdf, date accessed 1 August 2007.

11. Cranor, L. \& Cytron, R. (1997): Sensus: A SecurityConscious Electronic Polling System for the Internet, In Proceedings of the 30th Annual Hawaii International Conference on System Sciences, Wailea, Hawaii.

12. D. P. Gilliam, T. L. Wolfe, J. S. Sherif, and M. Bishop (2003): Software Security Checklist for the Software Life Cycle, in Proc. WETICE'03, 2003, pp. 243-248.

13. Feras, A. H., Mutaz, K. H. and Khairall, M. A. (2011): New applied e-voting system; Journal of Theoretical and Applied Information Technology, 25(2), ISSN: 1992-8645, pp. 88-97.

14. Fujioka, A., Okamoto, T. and Ohta, K. (1992): A Practical Secret Voting Scheme for Large Scale Elections", Workshop on the Theory and Application of Cryptographic Techniques - In Proceedings of Auscrypt'92, Gold Coast, Australia, pp. 244-251.

15. Gritzalis D, editor. (2002): Secure electronic voting. Advances in information security, vol. 7. Kluwer Academic Publishers.

16. Hamilton, T. (2002): Will we, should we e-Vote. Technology Report. Toronto Star Nov. 4.

17. JANIPOP's Observation (2012): Use of Electronic Voting Machine in Bangladesh: by Professor Dr. Nazmul Ahsan Kalimullah, chairman of JANIPOP and Professor Dr. A.K.M. Reazul Hassan, national volunteer of JANIPOP.

18. Kevin Daimi, Katherine Snyder, and Robert James: Requirements Engineering for E-Voting Systems: Department of Mathematics and Computer Science, University of Detroit Mercy, Detroit, Michigan 48219, USA.

19. Krimmer Robert and Ronald Schuster (2008): The EVOTING READINESS INDEX, Competence Center for 
Electronic Voting and Participation (E-Voting.CC), Pyrkergasse 33/1/2, A-1190 Vienna, Austria, $3^{\text {rd }}$ International Conference on for Electronic Voting 2008.

20. Leenes, R., Svenson, J. (2003): ICT in the Voting Process - A Report on 17 European Countries: University of Twente, 2003.

21. Loncke M. and J. Dumortier (2004): Online voting: a legal perspective, International Review of Law, Computers \& Technology, vol. 18 (1), pp 59-79.

22. Nurmi, H., Salomaa, A., and Santean, L. (1991): Secret ballot elections in computer networks. Computers and Security, 36 (10), pp. 553-560.

23. Obaed, Shama. (2011): Disadvantages of electronic voting, [online], Bangladesh Independent News Network. diakses 11 Juni 2011, http://www.bdinn.com/articles/ disadvantages-of-electronic -voting/ (accessed 11/06/2011).

24. ORG, (2007): Electronic Voting. A challenge to democracy? Retrieved on 7th December, 2012 from http://www.openrightsgroup.org/uploads/org-evotingbriefing-pack-final.pdf

25. Pinto, J. and Slevin, D. (1987): Critical Factors in Successful Project Implementation. IEEE Transactions on Engineering Management, 34(1), 22-27.
26. Remmert, M. (2004): Toward European Standards on Electronic Voting", [online], The Council of Europe, http://subs.emis.de/LNI/Proceedings/Proceedings47/Proce eding.GI. 47-1.pdf (accessed 24/12/2011).

27. Susanne, C. (2010): E-voting handbook; Key steps in the implementation of e-enabled elections, Council of Europe, ISBN 978 92-871-6948-8.

28. Tadayoshi, K., Adam, S., Aviel, D. R. and Dan, S. W. (2004): Analysis of an electronic voting system. IEEE Computer Society Press.

29. Trechsel, A.H. (2005): Curing democracy's ills? Modern technology and democratic procedures, Reflections on the future, pps. 45-50.

30. Ülle Lepp and Erik Loide (2007): E-VOTING - A KEY TO INDEPENDENCE FOR ALL: Conference \& Workshop on Assistive Technologies for People with Vision \& Hearing Impairments Assistive Technology for All Ages CVHI 2007, M.A. Hersh (ed.)

31. Zissis, D. and Lekkas (April 2011): "Securing eGovernment and e-Voting with an open cloud computing architecture". Government Information Quarterly 28 (2): 239-251. 